\section{BMJ Global Health}

\title{
Assessing the efficiency of countries in making progress towards universal health coverage: a data envelopment analysis of 172 countries
}

\author{
Emma Jordi, ${ }^{1}$ Caitlin Pley, ${ }^{2}$ Matthew Jowett, ${ }^{3}$ Gerard Joseph Abou Jaoude (D) , \\ Hassan Haghparast-Bidgoli ${ }^{1}$
}

To cite: Jordi E, Pley C, Jowett $\mathrm{M}$, et al. Assessing the efficiency of countries in making progress towards universal health coverage: a data envelopment analysis of 172 countries. BMJ Global Health 2020;5:e002992. doi:10.1136/ bmjgh-2020-002992

\section{Handling editor Lei $\mathrm{Si}$}

- Additional material is published online only. To view, please visit the journal online (http://dx.doi.org/10.1136/ bmjgh-2020-002992).

Received 24 May 2020 Revised 6 September 2020 Accepted 28 September 2020

Check for updates

\section{(c) Author(s) (or their} employer(s)) 2020. Re-use permitted under CC BY-NC. No commercial re-use. See rights and permissions. Published by BMJ.

${ }^{1}$ Institute for Global Health, University College London, London, UK

${ }^{2}$ School of Clinical Medicine, University of Cambridge, Cambridge, UK ${ }^{3}$ Health Financing and Governance, World Health Organization, Geneva, Switzerland

\section{Correspondence to}

Dr Hassan Haghparast-Bidgoli; h.haghparast-bidgoli@ucl.ac.uk

\section{ABSTRACT}

Introduction Maximising efficiency of resources is critical to progressing towards universal health coverage $(\mathrm{UHC})$ and the sustainable development goal (SDG) for health. This study estimates the technical efficiency of national health spending in progressing towards $\mathrm{UHC}$, and the environmental factors associated with efficient UHC service provision.

Methods A two-stage efficiency analysis using Simar and Wilson's double bootstrap data envelopment analysis investigates how efficiently countries convert health spending into UHC outputs (measured by service coverage and financial risk protection) for 172 countries. We use World Bank and WHO data from 2015. Thereafter, the environmental factors associated with efficient progress towards UHC goals are identified.

Results The mean bias-corrected technical efficiency score across 172 countries is $85.7 \%$ (68.9\% for low-income and 95.5\% for high-income countries). High-achieving middleincome and low-income countries such as El Salvador, Colombia, Rwanda and Malawi demonstrate that peer-relative efficiency can be attained at all incomes. Governance capacity, income and education are significantly associated with efficiency. Sensitivity analysis suggests that results are robust to changes.

Conclusion We provide a 2015 baseline for cross-country UHC technical efficiency scores. If countries wish to improve their UHC outputs within existing budgets, they should identify their current efficiency and try to emulate more efficient peers. Policy-makers should focus on strengthening institutions and implementing known best practices to replicate efficient systems. Using resources more efficiently is likely to positively impact UHC coverage goals and health outcomes, and without addressing gaps in efficiency progress towards achieving the SDGs will be impeded.

\section{BACKGROUND}

Following the successes of the millennium development goals, the United Nations introduced 17 sustainable development goals (SDGs) to continue progress on global development. Within SDG 3 ('Ensure healthy lives and promote well-being for all at all ages'), target 3.8 aims to 'achieve universal health coverage (UHC),

\section{Key questions}

What is already known?

- High-income countries tend to be more efficient than low/middle-income countries in converting their health resources into health outcomes (increased life expectancy).

- Robust methodologies exist for comparing the technical efficiency of different countries but have not before been applied to a global set of countries to assess the efficiency with which health spending converts to universal health coverage (UHC) indicators.

\section{What are the new findings?}

- Although countries with higher incomes tend to be more efficient, some low-income and middle-income countries outperform higher income counterparts.

- The main drivers of efficiency in achieving UHC are governance, income and education.

\section{What do the new findings imply?}

- Efficiency is an important measure of progress on achieving UHC. This study serves as a benchmark on UHC efficiency prior to the introduction of the sustainabledevelopment goals (SDGs), enabling future work to draw comparisons of pre-SDG and post-SDG.

- Countries who perform relatively poorly (low efficiency) could learn from better performing peers and replicate efficient strategies to avoid wastage of resources while improving health outcomes.

including financial risk protection, access to quality essential healthcare services and access to safe, effective, quality and affordable essential medicines and vaccines for all'. ${ }^{1}$ UHC comprises three dimensions: covering more people, offering more services and increasing financial protection. Although no country will ever reach $100 \%$ of services for $100 \%$ of its people at no cost to the individual, progress is being made, although with each country following its unique path. ${ }^{2}$ Performance management and efficiency 
are considered priorities for public health systems, ${ }^{3}$ crucial to accelerate progress on health outcomes at times of slow economic growth and health budget limitations. ${ }^{4}$

WHO estimates that half of the world's population cannot access basic essential services, and in 2015, $12.7 \%$ of the global population experienced catastrophic health expenditures (out-of-pocket payments (OOP) greater than $10 \%$ of their household budgets). ${ }^{5}$ There are stark global inequalities in both healthcare provision and health. Health and other inequalities leading to ill-health (eg, education, social behaviours, income and so on) exist both between and within countries, yet some countries have been able to achieve relatively better outcomes than peers with similar levels of income. ${ }^{6}$ UHC aims to address within-country and cross-country inequalities in health by providing an underlying level of access to care for all individuals within a population. Other social inequalities ought to be addressed via other public and social interventions but are considered in this paper as factors associated with health status.

At this stage, it is unknown how efficiently different countries use their resources to progress towards UHC coverage goals. The WHO established performance measurement and efficiency as priorities for public health systems worldwide. ${ }^{3}$ Given growing and ageing populations, fiscal constraints, competing development priorities, an expansion of healthcare options and providers, and an increased need for healthcare with a rising prevalence of non-communicable diseases, healthcare budgets are increasingly restricted and thus optimising health inputs to produce maximum health outcomes is a paramount management objective of public health systems. WHO has estimated that $20 \%-40 \%$ of health systems' resources are wasted, ${ }^{2}$ thereby undermining service delivery. By reducing inefficiencies, welfare gains can be achieved in the absence of budget increases. This paper measures how efficiently countries convert existing resources into UHC, providing a benchmark of UHC performance in 2015, when the SDGs were introduced, and enabling crosscountry comparisons going forward. Specifically, three questions are posed: (1) how efficient are different countries at converting healthcare inputs into UHC coverage goals? (2) what factors are associated with efficiency? and (3) what lessons can guide the efficient provision of UHC for countries going forward? This paper improves on the existing literature in four ways: first, it focuses on UHC service provision rather than health systems outcomes in general; second, it includes 172 countries in the analysis compared with smaller sample sizes found in other studies; third, it uses a complete service coverage index and finally, it applies a more robust and refined efficiency measurement technique.

\section{METHODS}

\section{Data envelopment analysis (DEA)}

DEA is a widely used linear programming technique to measure performance in healthcare because it offers a deterministic relationship between resource inputs and health outcomes, and can incorporate several inputs and outputs simultaneously. ${ }^{4}$ DEA calculates a relative efficiency score for decision-making units (DMUs) based on an optimally weighted allocation for a set of inputs and outputs. DMUs, countries in this analysis, receive scores between 0 (least efficient) and 1 (most efficient) with the efficient DMUs forming a production frontier that envelopes others, and to which all inefficient DMUs are compared. DEA models define efficiency as the weighted sum of outputs to the weighted sum of inputs, comparing how well countries convert inputs into outputs. Inefficiency is then the ratio of actual to 'optimal' performance. $^{8}$

DEA models can be input-oriented or output-oriented. The former minimises inputs for a constant set of outputs while the latter maximises outputs while holding inputs constant. This paper uses output-oriented DEA because changes to inputs are unlikely to take place in the short term in complex national health systems. ${ }^{9}$ This approach is consistent with the existing literature, which has opted for output orientation in health system DEA ${ }^{9-11}$ given that changes to inputs are unlikely to take place in the short-run and managers have little discretion over budget allocations. ${ }^{1213}$ Decentralised systems have far less control over how local units' budgets are allocated and cannot necessarily reallocate inputs. ${ }^{14}$ Countries with large private healthcare markets or relying on donor aid also have little influence over how healthcare is organised. A description of the DEA algorithm can be found in online supplemental materials S1 and S2.

\section{Secondary analysis}

The two-stage DEA investigates the factors associated with the estimated efficiency scores. Simar-Wilson bootstrapping $^{15}$ is a two-stage DEA method that has been widely applied in analyses at the national, regional, hospital and ward levels. ${ }^{12} 1617$ The Simar-Wilson method adjusts the standard DEA score by the amount of bias caused by contextual factors. In the second stage, the bias-corrected efficiency scores are regressed in a truncated model against explanatory variables suspected of impacting the outputs, which corrects the estimates from serial correlation and measurement error of the technical efficiency scores. ${ }^{18}$ Repeated samples are drawn with replacement, thus approximating the true sampling distribution of the DEA and subsequently estimating CIs not suffering from bias. In this study, 1000 bootstrap iterations are performed, thus allowing for a good approximation of $95 \%$ CIs. ${ }^{15}$ The result measures technical efficiency, the ratio of actual output to maximum possible output or minimum possible input to actual input, ${ }^{19}$ alongside the estimated bias-corrected efficiency scores.

\section{Data sources}

Cross-sectional data for health systems and environmental variables were obtained from the WHO Global Health Observatory and Global Health Expenditure Database, ${ }^{20}$ and the World Bank's World Development Indicators for 193 countries. ${ }^{21}$ Countries with missing data were excluded. Countries were grouped by income according to 2015 World Bank classifications. Patients 
and public were not involved in the research given that this was not relevant to the study.

\section{Outputs}

While progress has been made in compiling service coverage data, financial protection data remain sparse and outdated. ${ }^{22}$ Typically, cross-country performance reviews include outputs such as life expectancy and mortality rates to reflect overall population health. ${ }^{23-25}$ However, UHC coverage targets and indicators are more directly related to healthcare spending than health outcomes (eg, life expectancy and mortality) are, and therefore we opt to use UHC outputs as a more accurate reflection of the association between health spending and health outcomes. ${ }^{17}$ To measure UHC attainment, two indicators from the UHC Monitoring Framework are used as output variables. ${ }^{26}$

\section{UHC service coverage index}

This WHO-produced index variable comprises 16 tracer indicators relating to reproductive, maternal and child health; non-communicable diseases; communicable diseases; and service capacity and access. ${ }^{27}$ The index values for 2015 are available for all countries.

\section{Proxy for financial risk protection}

In the absence of complete data on financial risk protection, one minus OOPs (1-OOPs) as a proportion of current health expenditure (CHE) is used as a proxy for impoverishing spending. As data availability improves, catastrophic health expenditure (defined as OOPs exceeding a threshold of total household consumption ${ }^{22}$ ) should replace 1-OOPs/CHE as the output.

Combining these two outputs is important since they must be obtained simultaneously. High levels of service coverage is ineffectual if it leads to impoverishment; reduced OOP could reflect both good state-funded provision of care or low uptake of services due to cost barriers. To reflect this, the model is required to assign each output a weight greater than 0 , forcing the model to include both.

\section{Inputs}

The input is CHE in 2015 int \$. A 5-year average from 2011 to 2015 is used to reflect a lag in outputs and to smooth outliers and/or mismeasurement in the data. The paper considers CHE rather than government expenditure (as conducted previously by Jowett and colleagues ${ }^{17}$ ) because this includes other forms of health financing, including private pooled insurance and OOPs. If private input contributions were not included, service coverage would appear relatively more efficient for those countries with higher proportions of private payments.

\section{Second-stage DEA: what explains variations in efficiency?}

UHC efficiency can be explained by social, political, economic or environmental explanatory factors. Isolating those associated with UHC efficiency could highlight focus areas for policy-makers and control for inherent biases caused by factors outside of the health system. We expect variables such as income, governance, education and health system capital (number of beds and doctors) to be associated with efficiency. Detailed variable descriptions and their expected relationship with technical efficiency are presented in the online supplemental material S3.

\section{Key statistics for inputs, outputs and explanatory variables}

Descriptive statistics (included in online supplemental material S4) highlighted the unequal distribution of healthcare globally. Per capita health expenditure ranges from \$23.4 in the Democratic Republic of the Congo (DRC) to $\$ 8181.5$ in the USA. Even within low-income countries, Haiti spends seven times more ( $\$ 159.8$ per capita) than DRC. Similarly, $76 \%$ of expenditure on health in Yemen is out-of-pocket, compared with almost $0 \%$ in Kiribati. Average service coverage and government expenditure steadily increase across income groups. Electricity access more than doubles between low-income and lower-middle income countries. Education and governance appear to increase as income rises. Health worker density and number of beds increase steadily across income groups. Overall, country health profiles are heterogeneous, with trends favouring high-income countries.

\section{Model specifications}

The second-stage analysis included a Simar-Wilson bootstrap (Algorithm \#2) to test bias-corrected variable returns-to-scale (VRS) efficiency scores against environmental variables to investigate which factors are associated with how efficiently countries provide UHC. The paper uses VRS rather than constant returns-to-scale because countries do not operate as optimal scales, whereby an increase in inputs produces a proportionate increase in output. ${ }^{28}$ This analysis could aid policy-makers in determining which actions to take in order to reach UHC goals more efficiently, given the current level of national spending. Nine potential environmental variables were considered for inclusion in the double bootstrap regression. Spearman's rank correlation showed strong, but not severe correlation, with 0.7526 being the highest correlation value between education and governance. The main model includes eight environmental factors with data for all 172 countries, while the secondary model includes these eight plus the Gini Index, which had data available for 145 countries. Service coverage prioritises equityseeking countries and inequality might impact efficiency. Therefore, the secondary model captures the effect of within-country inequalities.

\section{Sensitivity analysis}

To assess the robustness of the findings, given that DEA can produce sensitive results, an in-depth sensitivity analysis was performed. The following adjustments were made to determine the robustness of results: 


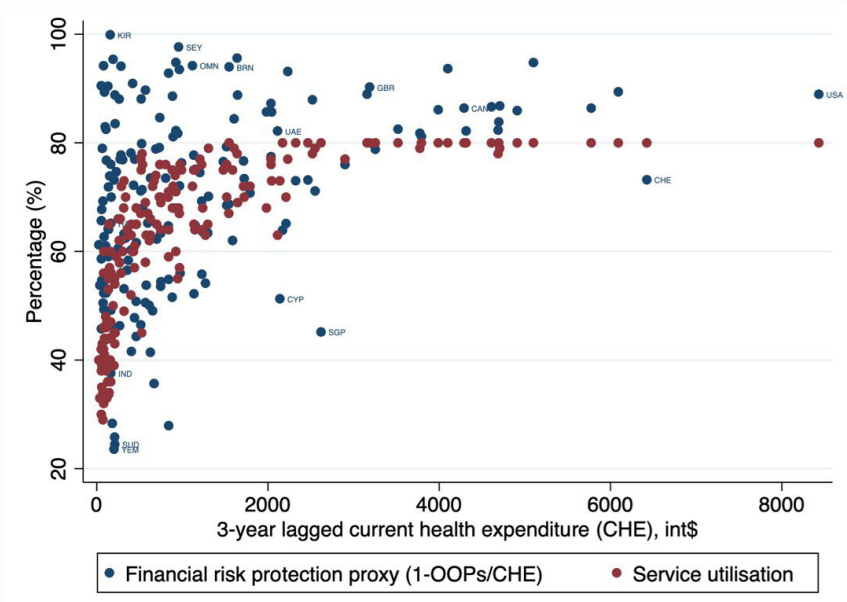

Figure 1 UHC indicators by current health expenditure. CHE, current health expenditure; OOP, out-of-pocket payment; UHC, universal health coverage.

1. The financial protection proxy, 1-OOPs/CHE, was substituted with domestic general government expenditure (GGHE-D)/CHE, which is a similar and alternative proxy for financial protection, but without considering private pooled insurance.

2. 3-year lag for CHE were used in place of the 5-year lagged average to test the sensitivity of the time lag.

3. Outlying countries were removed one at a time, since deterministic models like DEA do not allow for random noise and are particularly sensitive to outliers.

4. Tobit regression as an alternative methodology was used as second stage in place of Simar-Wilson.

\section{RESULTS}

There is an exponential relationship globally between health expenditure and both UHC indicators (figure 1). Initially, small increases in health expenditure yield large changes in service coverage and financial protection. Yet, as levels of health expenditure rise, the marginal improvement to UHC outputs diminishes. There are decreasing marginal returns because the most costeffective programmes are typically implemented first. From figure 1, it appears that there is little additional benefit when spending more than $\$ 2000$ per capita. However, this is partly because the service coverage indicator omits the benefits of secondary-level and tertiarylevel spending outside of the 16 tracer indicators, which reflect primary care coverage. Under $\$ 2000$ per capita, large health gains are associated with marginal additional expenditure.

\section{Technical efficiency of converting health spending into UHC outputs}

Table 1 indicates that high-income countries can improve their efficiency by up to $5 \%$. By comparison, low-income countries can produce $31 \%$ more UHC outputs under full efficiency. These findings suggest high-income countries on average produce UHC outputs more efficiently than other income groups after correcting for bias. Top performers by income group are Switzerland, Austria and Belgium (high income), Colombia, Brazil and Peru (upper-middle income), El Salvador, Samoa and Vietnam (lower-middle income) and Malawi, Zimbabwe and Rwanda (low income).

\section{Associations of technical efficiency}

Results from the Simar-Wilson bias-corrected regression identify three variables that were statistically significantly associated with a country's technical efficiency (table 2). These are: (a) Gross Domestic Product (GDP) per capita, (b) governance capacity and (c) education. Higher income, better governance and more years of schooling within a country are associated with greater technical efficiency in converting health spending to UHC goals. Governance has the strongest relationship with efficiency and a one unit increase in governance could lead to a 0.06-unit improvement in UHC service goals, keeping health expenditure constant.

When including the Gini index for a secondary model with a subset of 145 countries, findings suggest that inequality is significantly positively associated with technical efficiency but results in governance becoming insignificant. Countries with more inequality tend to more efficiently provide UHC. This is the opposite of what is to be expected and therefore this result should be interpreted cautiously.

\section{Sensitivity analysis of efficiency scores}

The sensitivity analysis demonstrated that the results of this study are largely robust (further details in online supplemental material S5). Substituting the financial protection proxy to GGHE-D/CHE had an average effect of $0.1 \%$ across all countries' bias-corrected efficiency scores and resulted in income becoming insignificant and electricity significant. Removing efficient and outlier DMUs did not substantially impact results, with three countries moving more than $5 \%$ on average and none changing more than 7\%. Education, GDP per capita, governance and electricity were significant when using a Tobit regression instead of a Simar-Wilson bootstrap.

\section{DISCUSSION}

\section{Associations of efficiency}

This paper estimates how efficiently total health expenditure per capita is converted into UHC service goals for 172 countries in 2015 and provides a pre-SDG baseline for future analyses. We address a gap in the literature on UHC efficiency by using most recent UHC data and applying a more robust methodology, specifically DEA with a double bootstrap truncated regression analysis, to more countries than in previous studies. Given large heterogeneity across countries, comparisons are made within peer groups.

The main study findings suggest that although highincome countries tend to outperform lower income countries, some countries such as Colombia, El Salvador 
Table 1 Summary of bias-corrected Shepherd efficiency scores by income group (full results in online supplemental material S4)

\begin{tabular}{|c|c|c|c|c|c|}
\hline & \multicolumn{5}{|l|}{ Income group } \\
\hline & Low income & $\begin{array}{l}\text { Lower-middle } \\
\text { income }\end{array}$ & Upper-middle income & High income & All countries \\
\hline Mean & 0.69 & 0.82 & 0.88 & 0.95 & 0.86 \\
\hline SD & $(0.11)$ & $(0.10)$ & $(0.07)$ & $(0.05)$ & $(0.12)$ \\
\hline Maximum & 0.86 & 0.96 & 0.97 & 1 & 1 \\
\hline Top 3 & $\begin{array}{l}\text { Malawi, Rwanda, } \\
\text { Zimbabwe }\end{array}$ & $\begin{array}{l}\text { El Salvador, Samoa, } \\
\text { Vietnam }\end{array}$ & $\begin{array}{l}\text { Angola, Bosnia and } \\
\text { Herzegovina, Albania }\end{array}$ & $\begin{array}{l}\text { Latvia, Lithuania, } \\
\text { United Arab } \\
\text { Emirates }\end{array}$ & $\begin{array}{l}\text { Malawi, Rwanda, } \\
\text { Zimbabwe }\end{array}$ \\
\hline Bottom 3 & $\begin{array}{l}\text { Mali, Sierra Leone, } \\
\text { Afghanistan }\end{array}$ & $\begin{array}{l}\text { Mauritania, Sudan, } \\
\text { Yemen }\end{array}$ & Colombia, Peru, Brazil & $\begin{array}{l}\text { Switzerland, } \\
\text { Austria, Belgium }\end{array}$ & $\begin{array}{l}\text { Switzerland, } \\
\text { Austria, Belgium }\end{array}$ \\
\hline
\end{tabular}

and Malawi outperform their income group peers. This implies that for a given level of resources and spending, peers could increase their performance and increase their outcomes against UHC indicators. Peers should emulate best practice approaches that these outperforming countries have taken, to the extent that they are compatible in the national and local context. Simar-Wilson bootstrap results suggest that, in the main model, GDP per capita (income), governance capacity and education have a statistically significant relationship with how efficiently a country can convert spending into UHC service goals.

The mean efficiency scores by income group after biascorrection were $95 \%$ (SD 0.05), 88\% (SD 0.07), 82\% (SD 0.10 ) and $69 \%$ (SD 0.11) for high, upper-middle, lowermiddle and low-income countries respectively. The lowest score was $49.9 \%$ for Mali. Figure 2 shows the distribution of bias-corrected efficiency scores within income groups.

\section{There are opportunities to improve efficiency}

Many countries, particularly low or middle income, can drastically improve the efficiency with which they provide UHC. Specific policy changes should be investigated further for contextual, evidence-based and implementable advice for decision-makers at national levels. We show that there are three ways to improve efficiency. The first is reducing healthcare expenditure, holding all else constant. Most countries showed decreasing returns to scale in the DEA. Covering more people becomes increasingly costly since hard-to-reach individuals are covered last, at greater cost. Countries with worse health outcomes are likely to experience the effects of diminishing marginal returns, where initial returns to investment are high and decrease as the investment increases. As countries spending little spend more, the gap in spending will close and efficiency gains from low spending will be less pronounced. To improve efficiency at already high levels of expenditure, countries require an even greater focus on efficiency to improve health outcomes. This said, even at higher marginal costs, governments should continue to prioritise health spending given the direct relationship with health and quality of life associated therewith. Three common drivers in countries' UHC trajectories include: political reforms in favour of UHC; income growth and increased health spending; and increased pooled spending over OOP. ${ }^{29}$ Thus, increasing health spending will help countries progress towards achieving UHC. Highly privatised health systems are also considered more inefficient than public ones, and therefore countries should try to reduce fragmentation and move towards unitary publicly financed health systems to improve efficiency. ${ }^{30}$

More services can be provided for the same expenditure by reallocating and diversifying resources towards most cost-effective programmes, thereby covering more essential services. For example, Chad and DRC have low scores for access to modern family planning methods and tuberculosis treatment coverage. Increasing service coverage from the lowest score to the highest is associated with 21 years of additional life. ${ }^{27}$ One way to reduce costs

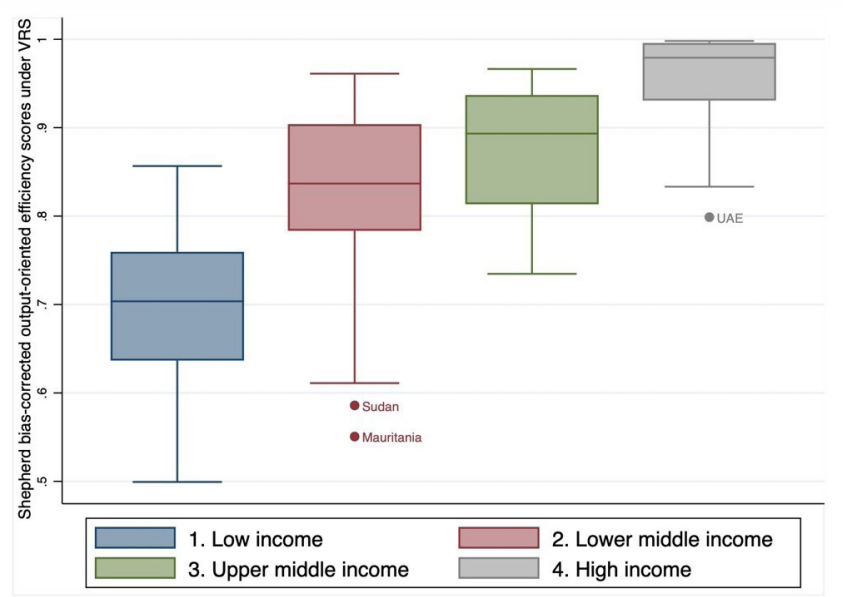

Figure 2 Distribution of VRS bias-corrected efficiency scores by income group. VRS, variable returns-to-scale. 
Table 2 Associations of Simar-Wilson bias-corrected efficiency scores

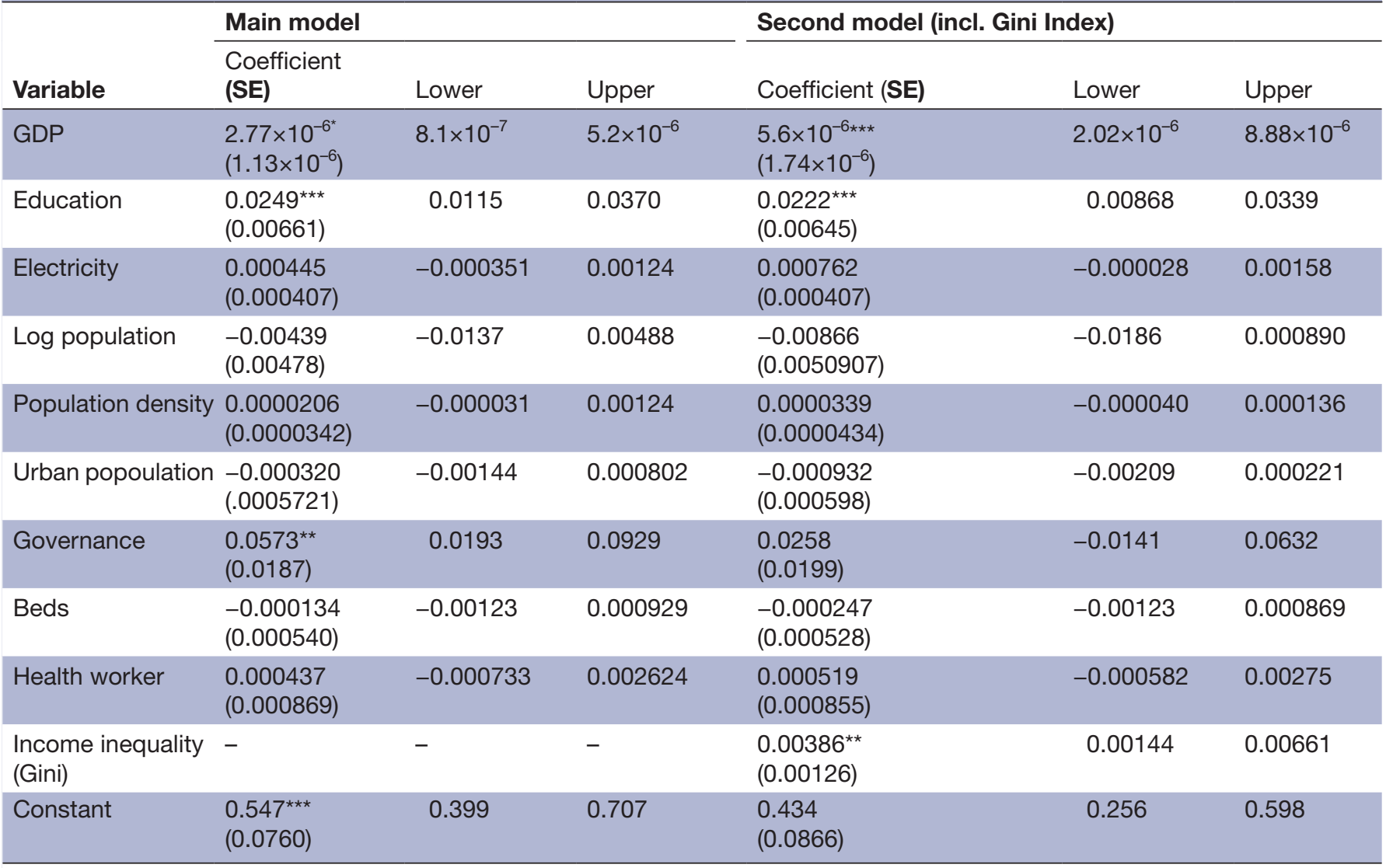

${ }^{*} \mathrm{p}<0.05,{ }^{* *} \mathrm{p}<0.01,{ }^{* * *} \mathrm{p}<0.001$.

$n=172$ for main model, $n=145$ for secondary model.

GDP, Gross Domestic Product.

and provide more services would be a shift to primary and preventative healthcare, which often requires improving step-down facilities and procedures for referral. ${ }^{30}$

\section{Good governance matters}

Good local governance plays a significant role in achieving UHC service goals efficiently, according to our results. The role of strong governance mechanisms in allocating health resources most efficiently and effectively, thereby improving health coverage and status, is recognised in the context of maternal and child health, a key dimension of UHC. ${ }^{31}$ More broadly, one leading theory on the causative processes leading to economic growth and development suggests that development is reliant on institutions. ${ }^{32}$ We have shown that governance (defined as institutional strength, institutional memory and political commitment) are key to achieving UHC coverage goals. Political engagement, ideally at the highest levels of government, is also a likely prerequisite to achieving UHC efficiency improvements.

In addition to developing local governance, policymakers can seek guidance from global governance mechanisms and non-state actors which also play a critical role in local delivery of health programmes, through collective action and developing norms and standards. ${ }^{33}$ Good governance practices supported by national and supranational health actors, including governments, large donors and international organisations, should be locally tailored to suit national interests before being implemented but can provide pragmatic solutions to delivering care equitably, effectively and cost efficiently.

\section{Efficiency gains can compound}

While producing more outputs for the same level of inputs is itself valuable, efficiency gains may support requests for budget reallocation towards healthcare if ministries can prove to national treasuries or aid donors that they are attaining a high return on investment. Funds may migrate towards programmes or countries providing efficient UHC services.

\section{Does income matter?}

Income is significant in both the main model and the secondary (includes Gini Index). Both models demonstrate clear trends in UHC provision efficiency by income group. Lower efficiency scores are predominantly seen among lower income nations, many of which suffer from political, economic and regional instability. Yet, lower income does not eliminate the possibility for countries to perform efficiently. El Salvador, Samoa and Vietnam (lower-middle-income) have scores higher than some high-income countries (for example Estonia, Bahrain 
and Slovakia) and Malawi (low-income) performs better than several upper-middle-income countries. Prior to bias correction, several low-income countries are equally as efficient as high-income countries, suggesting that income group does not eliminate the ability to provide UHC efficiently. ${ }^{24}$ Income likely aids efficiency, but UHC efficiency can be attained at any income level with the right supporting factors in place.

Our findings that income (GDP per capita), education and governance are related to how efficiently countries convert health spending into UHC are aligned with findings from similar studies (although these look at healthcare not UHC). ${ }^{34}{ }^{35}$ Standard cross-country efficiency studies are frequently criticised in that measures of health (typically life expectancy and mortality) are highly influenced by factors widely outside the health system. ${ }^{36}$ Our approach better withstands this criticism since it is measuring the efficiency of the health system's ability to produce UHC service goals (a direct relationship) and not good health generally (an indirect relationship).

We explored the relationship between UHC efficiency and good health more generally, which is the ultimate goal of UHC provision. UHC is important for achieving good health outcomes ${ }^{37}$ but the relationship between how efficiently UHC is provided and good health has not been investigated. Figure 3 shows a strong linear relationship between bias-corrected technical efficiency scores and health-adjusted life expectancy (HALE) in the following year. Since the latest data on HALE are from 2016, and historical UHC data are not available, a time lag could not be incorporated and a full regression analysis should be performed when the data become available.

DEA methodology has intrinsic limitations. It is deterministic, relying heavily on the data selected; it is only as good as the data that inform it and cannot perform where data are absent, nor can it produce useful estimates if the underlying data are inaccurate. Additionally, DEA

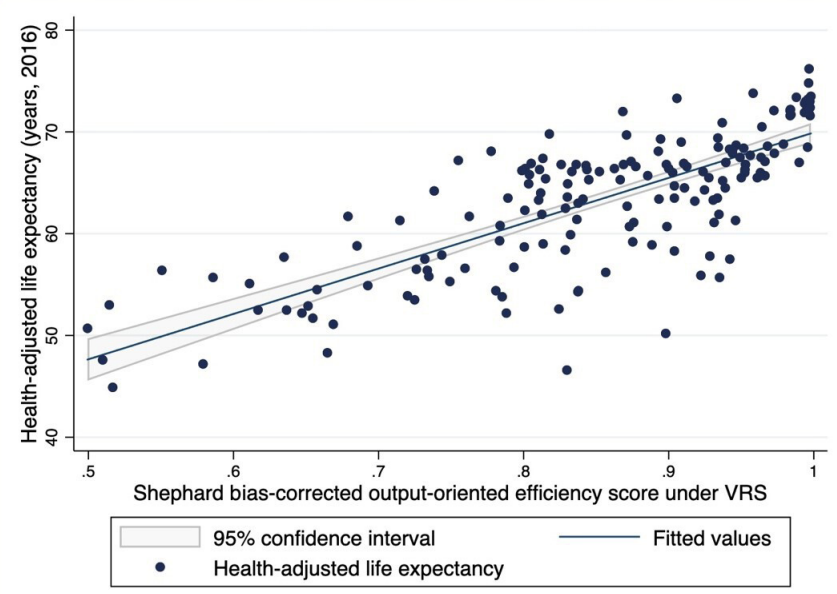

Figure 3 Relationship between bias-corrected technical efficiency scores and HALE in the following year. HALE, health-adjusted life expectancy; VRS, variable returns-toscale. provides a relative measure of each unit to 'perfectly efficient' peers scoring one, and so including or excluding certain peers could influence the relative performance and results. The methodology assumes a homogeneous production function, which is unrealistic, as not all countries have access to the same human capital and technology. Efforts should be made to complete datasets for countries with missing health systems data to avoid the need for a financial protection proxy. The choice of variables used for the second-stage analysis was largely dependent on data availability. Many of these limitations have been addressed through sensitivity analysis. The conclusions drawn from the findings remained largely consistent despite adjustments to the models. Further studies could investigate the optimal combination of primary to secondary/tertiary care maximum efficiency or the effects of UHC efficiency on HALE. These questions require more nuanced healthcare data.

\section{CONCLUSION}

These findings provide a benchmark for the efficiency that countries convert expenditure to UHC, offering a useful comparison for post-SDG studies assessing progress towards UHC attainment. This study fills a literature gap in UHC-specific efficiency analysis and benefits from its wide country coverage and its robust methodology. The findings suggest that although high-income countries tend to outperform lower income countries, some countries such as Colombia, El Salvador and Malawi outperform their income group peers. Peer countries could emulate some of the best practice approaches these countries have taken, to the extent that they are compatible in the national and local context. Better governance, improved education, higher GDP per capita and Gini Index are significantly associated with how efficiently countries convert total health expenditure into UHC. Health outputs, such as UHC efficiency, may be better indicators than health outcomes to guide national policy development for health system strengthening, as health outputs have a more direct relationship with national health spending. Efficiently producing UHC is likely to positively impact health outcomes, and without addressing gaps in efficiency, progress towards achieving the SDGs will be impeded.

Contributors $\mathrm{HH}-\mathrm{B}$ and EJ conceptualised the study. EJ collected and collated the data, carried out the analysis and wrote the first draft of the paper. $\mathrm{HH}-\mathrm{B}, \mathrm{CP}$, $\mathrm{MJ}$ and GJAJ contributed to the interpretation of the results and contributed to the final written version of the paper. All authors approved the final version of the manuscript.

Funding The authors have not declared a specific grant for this research from any funding agency in the public, commercial or not-for-profit sectors.

Competing interests None declared.

Patient consent for publication Not required.

Provenance and peer review Not commissioned; externally peer reviewed.

Data availability statement Data are publicly available from the WHO Global Health Observatory database, and may be shared directly upon request. 
Supplemental material This content has been supplied by the author(s). It has not been vetted by BMJ Publishing Group Limited (BMJ) and may not have been peer-reviewed. Any opinions or recommendations discussed are solely those of the author(s) and are not endorsed by BMJ. BMJ disclaims all liability and responsibility arising from any reliance placed on the content. Where the content includes any translated material, BMJ does not warrant the accuracy and reliability of the translations (including but not limited to local regulations, clinical guidelines, terminology, drug names and drug dosages), and is not responsible for any error and/or omissions arising from translation and adaptation or otherwise.

Open access This is an open access article distributed in accordance with the Creative Commons Attribution Non Commercial (CC BY-NC 4.0) license, which permits others to distribute, remix, adapt, build upon this work non-commercially, and license their derivative works on different terms, provided the original work is properly cited, appropriate credit is given, any changes made indicated, and the use is non-commercial. See: http://creativecommons.org/licenses/by-nc/4.0/.

ORCID iD

Gerard Joseph Abou Jaoude http://orcid.org/0000-0001-6022-3036

\section{REFERENCES}

1 United Nations. Transforming our world: the 2030 agenda for sustainable development. , 2015: 16301, 1-35.

2 Evans DB, Etienne C. Health systems financing and the path to universal coverage. Bull World Health Organ 2010;88:402.

3 Daher M. Overview of the world health report 2000 health systems: improving performance. J Med Liban 2001;49:1-215.

4 Cantor VJM, Poh KL. Integrated analysis of healthcare efficiency: a systematic review. J Med Syst 2018;42:1-23.

5 World Bank Group, World Health Organization. Global monitoring report on financial protection in health 2019, 2019. Available: https:// data.worldbank.org/indicator/SH.UHC.OOPC.10.ZS [Accessed 06 Jan 2020].

6 Balabanova D, Mills A, Conteh L, et al. Good health at low cost 25 years on: lessons for the future of health systems strengthening. Lancet 2013;381:2118-33.

7 Hussey PS, De Vries H, Romley J, et al. A systematic review of health care efficiency measures: health care efficiency. Health Serv Res 2009;44:784-805.

8 Moreno-Serra R, Anaya-Montes M, Smith PC. Potential determinants of health system efficiency: evidence from Latin America and the Caribbean. PLoS One 2019;14:e0216620:1-21.

9 See KF, Yen SH. Does happiness matter to health system efficiency? A performance analysis. Health Econ Rev 2018;8:33.

10 Ahmed S, Hasan MZ, MacLennan M, et al. Measuring the efficiency of health systems in Asia: a data envelopment analysis. BMJ Open 2019;9:e022155.

11 Pérez-Cárceles MC, Gómez-Gallego JC, Gómez-Gallego M. Environmental factors affecting European and Central Asian healthsystems' bias-corrected efficiency. Appl Econ 2018;50:3432-40.

12 Achoki T, Hovels A, Masiye F, et al. Technical and scale efficiency in the delivery of child health services in Zambia: results from data envelopment analysis. BMJ Open 2017;7:e012321.

13 Mujasi PN, Asbu EZ, Puig-Junoy J. How efficient are referral hospitals in Uganda? A data envelopment analysis and tobit regression approach. BMC Health Serv Res 2016;16:230

14 Yang C-C. Measuring health indicators and allocating health resources: a DEA-based approach. Health Care Manag Sci 2017;20:365-78.

15 Simar L, Wilson PW. Estimation and inference in two-stage, semi-parametric models of production processes. $J$ Econom 2007;136:31-64.
16 Bobo FT, Woldie M, Wordofa MA, et al. Technical efficiency of public health centers in three districts in Ethiopia: two-stage data envelopment analysis. BMC Res Notes 2018;11:465.

17 Jowett M, Cylus J. Spending targets for health: no magic number health financing working paper No. 1.Work Pap, 2016. Available: http://apps.who.int/iris/handle/10665/250048

18 Lépine A, Vassall A, Chandrashekar S. The determinants of technical efficiency of a large scale HIV prevention project: application of the DEA double bootstrap using panel data from the Indian Avahan. Cost Eff Resour Alloc 2015;13:1-11.

19 Hollingsworth $\mathrm{B}$. The measurement of efficiency and productivity of health care delivery. Health Econ 2008;17:1107-28.

20 WHO. Global health expenditure data, 2019.

21 World Bank Group. World development indicators, 2019.

22 Wagstaff A, Flores G, Hsu J, et al. Progress on catastrophic health spending in 133 countries: a retrospective observational study. Lancet Glob Health 2018;6:e169-79.

23 Hadad S, Hadad Y, Simon-Tuval T. Determinants of healthcare system's efficiency in OECD countries. Eur J Health Econ 2013:14:253-65

24 Retzlaff-Roberts D, Chang CF, Rubin RM. Technical efficiency in the use of health care resources: a comparison of OECD countries. Health Policy 2004;69:55-72.

25 Evans DB, Tandon A, Murray CJL, et al. Using data envelopment analysis to address the challenges of comparing health system efficiency. Glob Policy 2017;3:60-8.

26 World Bank Group, World Health Organisation. Tracking Universal Health Coverage : 2017 Global Monitoring Report. Washington DC, Geneva, 2017.

27 Hogan DR, Stevens GA, Hosseinpoor AR, et al. Monitoring universal health coverage within the sustainable development goals: development and baseline data for an index of essential health services. Lancet Glob Health 2018;6:e152-68.

28 Jacobs R, Smith PC, Street A. Measuring efficiency in health care: Analytic techniques and health policy. Cambridge University Press, 2006.

29 Savedoff WD, de Ferranti D, Smith AL, et al. Political and economic aspects of the transition to universal health coverage. Lancet 2012;380:924-32.

30 Stuckler D, Feigl AB, Basu S, et al. The political economy of universal health coverage. background paper for the global Symposium on health systems research, 2010.

31 Wehrmeister FC, da Silva ICM, Barros AJD, et al. Is governance, gross domestic product, inequality, population size or country surface area associated with coverage and equity of health interventions? ecological analyses of cross-sectional surveys from 80 countries. BMJ Glob Health 2017;2:e000437.

32 Acemoglu D, Johnson S, Robinson JA. Institutions as a fundamental cause of long-run growth. Handb Econ growth 2005:1:385-472.

33 Fryatt R, Bennett S, Soucat A. Health sector governance: should we be investing more? BMJ Glob Health 2017;2:e000343.

34 Afonso A, St. Aubyn M. Assessing health efficiency across countries with a two-step and bootstrap analysis. Appl Econ Lett 2011;18:1427-30.

35 Ravangard R, Hatam N, Teimourizad A, et al. Factors affecting the technical efficiency of health systems: a case study of economic cooperation organization (Eco) countries (2004-10). Int $J$ Health Policy Manag 2014;3:63-9.

36 Cylus J, Papanicolas I, Smith PC. Health system efficiency how to make measurement matter for policy and management. London, 2016.

37 Moreno-Serra R, Smith PC. Broader health coverage is good for the nation's health : evidence from country level panel data, 2015: 101-24. 


\section{Supplementary Materials}

\section{S1. DEA Methodology in Detail}

Data Envelopment Analysis (DEA) uses linear programming techniques to assess how efficiently multiple inputs are able to produce multiple outputs, either by maximising outputs for a given set of inputs (output-oriented) or minimising inputs to achieve a certain output (input-oriented). DEA is a type of 'frontier analysis' meaning that the model output is a rank ordering of decision making units (DMUs) compared to a frontier of fully efficient DMUs. Thus, inefficient DMUs are enveloped by top performing units in multidimensional space (which depends on the number of inputs and outputs used). In this case, there is one input and two outputs and so the production frontier is a surface in three-dimensional space. Inefficiency is then measured as the distance from the DMU to the frontier; this is the amount by which the DMU can improve its outputs while maintaining the same level of inputs. The idea is thus to maximise the ratio of the sum of the outputs to the sum of the inputs, each weighted such that the DMU is "cast in the best light possible"; in other words, no alternative weights could improve the performance of the DMU.[28]

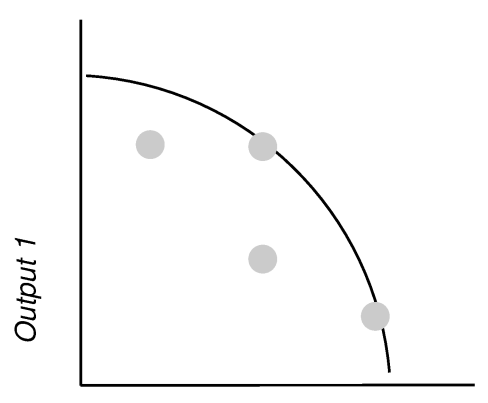

Output 2 
The optimisation problem is thus as follows:

$$
\max \left(\frac{\sum_{s=1}^{S} u_{s} y_{s 0}}{\sum_{m=1}^{M} v_{m} x_{m 0}}\right)
$$

subject to:

$$
\frac{\sum_{s=1}^{S} u_{s} y_{s i}}{\sum_{m=1}^{M} v_{m} x_{m i}} \leq 1 \quad \mathrm{i}=1, \ldots, \mathrm{l}
$$

where:

$y_{s 0}$ is the quantity of output $\mathrm{s}$ for $\mathrm{DMU}_{0}$;

$u_{s}$ is the weight of output $\mathrm{s}$ and $u_{s}>0$;

$x_{m 0}$ is the quantity of output $\mathrm{m}$ for $\mathrm{DMU}_{0}$;

$v_{m}$ is the weight of output $\mathrm{s}$ and $v_{m}>0$;

$$
\text { for } s=1, \ldots S \text { and } m=1, \ldots, M
$$

In the case of output maximisation, the sum of inputs must be held constant and thus the denominator is unity. The optimisation problem is therefore rewritten as follows:

$$
\operatorname{Max} \theta_{0}=\sum_{s=1}^{S} u_{s} y_{s 0}
$$

subject to:

$$
\sum_{m=1}^{M} v_{m} x_{m 0}=1
$$




$$
\sum_{r=1}^{s} u_{r} y_{r j}-\sum_{i=1}^{m} v_{m} x_{m i} \leq 0 i=1, \ldots n
$$

$$
u_{r}, v_{i} \geq 0
$$

These constraints ensure a denominator equal to one, that the sum of all outputs cannot exceed the sum of all inputs and that the weights for each variable must be strictly positive. This ensures that all inputs and outputs are present in the solution.

As a set of linear equations, this is written as follows:

$$
\begin{gathered}
\operatorname{Max}_{v, u} \theta_{0}=u y_{i} \\
\text { subject to: } \\
v x_{i}=1 \\
-v X+u Y \leq 0 \\
u, v \geq 0
\end{gathered}
$$

Where $x_{i}$ and $y_{i}$ represent input and output vectors for all I DMUs; $u, v$ are row vectors for input and output weights, and $\mathrm{X}, \mathrm{Y}$ are input and output matrices representing data for all I DMUs. $\theta$ is a scalar and $\theta \leq 1$, representing level of efficiency with one being fully efficient compared to peers. The minimisation problem for input-orientation is analogous to this. 
S2. Truncated regression bootstrap methodology[36]

Algorithm \#2 consists of the following steps (adapted from Badunenko and Tauchmann ${ }^{31}$ ):

1. Compute $\widehat{\theta}_{l}$ for all DMUs $i=1, \ldots, N$ using DEA.

2. Use those $M$ (with $M<N$ ) DMUs, for which $\hat{\theta}_{i}>1$ holds, in a truncated regression (left-truncation at 1) of $\hat{\theta}_{i}$ on $\mathbf{z}_{\mathbf{i}}$ to obtain coefficient estimates $\hat{\beta}$ and an estimate for variance parameter $\hat{\sigma}$ by maximum likelihood.

3. Loop over the following steps 3.1-3.4 $B_{1}$ times, in order to obtain a set of $B_{1}$ bootstrap estimates $\widehat{\theta_{l}^{b}}$. for each DMU $\mathrm{i}=1, \ldots, \mathrm{N}$, with $\mathrm{b}=1, \ldots, \mathrm{B}_{1}$.

3.1 For each $\mathrm{DMU} i=1, \ldots, \mathrm{N}$, draw an artificial error $\widetilde{\varepsilon_{l}}$ from the truncated $\mathrm{N}(0, \hat{\sigma})$ distribution with left-truncation at $1-\mathbf{z}_{i} \hat{\beta}$.

3.2 Calculate artificial efficiency scores $\widetilde{\theta_{l}}$ as $\mathbf{z}_{i} \hat{\beta}+\widetilde{\varepsilon_{l}}$ for each DMU $\mathrm{i}=1, \ldots, \mathrm{M}$.

3.3 Generate $i=1, \ldots, N$ artificial DMUs with input quantities $\widetilde{x_{l}}=x_{i}$ and output quantities $\widetilde{y}_{l}$ $=\left(\frac{\widehat{\theta}_{l}}{\widetilde{\theta}_{l}}\right) y_{i}$.

3.4 Use the $\mathrm{N}$ artificial DMUs, generated in step 3.3, as reference set in a DEA that yields $\widehat{\theta_{l}^{b}}$ for each original DMU $\mathrm{i}=1, \ldots, \mathrm{M}$.

4. For each $\mathrm{DMU} \mathrm{I}=1, \ldots, \mathrm{N}$, calculate a bias corrected efficiency score $\widehat{\theta_{l}^{b c}}$ as $\widehat{\theta_{l}}-$ $\left(\frac{1}{B_{1}} \sum_{b=1}^{B_{1}} \widehat{\theta_{l}^{b}}-\widehat{\theta_{l}}\right)$.

Calculate confidence intervals and standard errors for $\hat{\beta}$ and $\hat{\sigma}$ from the bootstrap distributions of $\hat{\beta}^{b}$ and $\hat{\sigma}^{b}$.

5. Run a truncated regression (left-truncation at 1) of $\widehat{\theta_{l}^{b} c}$ on $\mathbf{z}_{\mathrm{i}}$ to obtain coefficient estimates $\hat{\hat{\beta}}^{b}$ and $\hat{\sigma}^{b}$ by maximum likelihood.

6. Loop over the following steps $6.1-6.3 B_{2}$ times, in order to obtain a set of $B_{2}$ bootstrap estimates $\hat{\hat{\beta}}^{b}$ and $\hat{\sigma}^{b}$, with $\mathrm{b}=1, \ldots, \mathrm{B}_{2}$.

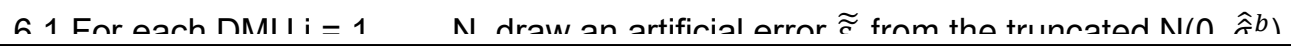

Figure 1: Truncated Bootstrap Regression, Algorithm \#2 


\section{S3. Variable descriptions}

\section{Gross Domestic Product (GDP) per capita}

Income plays an important role in the ability of countries to provide services across the 16 health indicators. Income is correlated to other development indicators (poverty and education for example) but is frequently used with these indicators in regression models. Average GDP per capita is used to indicate average income levels for countries and therefore their ability to pay for health services provision.

\section{Governance}

The World Bank's World Governance Indicators (WGI) consists of six measures on national governance: Voice and Accountability, Political Stability, Government Effectiveness, Regulatory Quality, Rule of Law and Control of Corruption. National governance is represented by the mean of these six variables, which are scored from -2.5 to 2.5. The variables are strongly correlated and therefore cannot be included in the regression model individually.

\section{Education}

The average number of years of schooling that a child of school entrance age can expect to receive is used as a measure of population level education.[9] Better education, particularly girl's education, is closely linked to improved overall population health, and also contributes to increased availability of trained health workers and better management in the health sector.[37]

\section{Inequality}

The Gini Coefficient is a unit-free measure of income inequality reflecting national difference in distribution of income. A score of 0 represents perfect equality and 1 represents perfect inequality.

\section{Electricity}

The percentage of the population with access to electricity is used for this indicator. Only a third of sub-Saharan African hospitals have reliable electricity provision, which particularly affect utilization of essential health care services.[38] Electricity access acts as a quality indicator. 


\section{Population size}

Population data are widely available and extracted from GHO for all countries. To reduce the spread of data, the natural logarithm is taken for all countries.

\section{Urbanisation}

The percentage of total population living in urban areas is used as the measure for this indicator. Service provision in urban populations is more cost-effective since they are easier to reach than rural populations.

\section{Population Density}

Population density (the number of people per square kilometer) could affect how efficiently care is delivered in facilities, as well as the distribution of medical supplies or demand for services. A higher population density could affect efficiency through economies of scale, as shown by a number of health system efficiency studies.[39,40]

\section{Inverse of $O O P$}

The inverse of OOP is an alternative measure of financial protection and represents the amount not paid for by users at the point of care. This incorporates donor expenditure, nongovernmental organisations and financial aid not considered in general government health expenditure output.

\section{Physician density}

Medical staff density (number of medical doctors per 100,000 people) is commonly used as the labour input in efficiency studies and was used in this study as a proxy for capacity of health systems to provide essential outpatients and primary health services. Ideally, a health worker density indicator that includes other staff such as community health workers, nurses and midwives, in addition to doctors, would be a better proxy but there is lack of comparable data across countries for other staff.

\section{Beds}

The number of hospital beds (per 100,000), which is commonly used as capital input in efficiency studies, was used as a proxy for the capacity of health systems to provide essential inpatient services. 
Descriptive Statistics of DEA and explanatory variables

\begin{tabular}{|c|c|c|c|c|c|c|c|c|c|c|c|c|c|c|c|c|c|c|c|c|}
\hline \multirow[t]{2}{*}{ Variable Name } & \multicolumn{4}{|c|}{ Low income } & \multicolumn{5}{|c|}{ Lower middle income } & \multicolumn{5}{|c|}{ Upper middle income } & \multicolumn{6}{|c|}{ High income } \\
\hline & $n$ & Mean & $S D$ & Min & Max & $n$ & Mean & $S D$ & Min & Max & $n$ & Mean & $S D$ & Min & $\operatorname{Max}$ & $n$ & Mean & $S D$ & Min & Max \\
\hline CHE per capita & 26 & 87.7 & 36.5 & 23.4 & 159.8 & 46 & 245.7 & 141.6 & 70.3 & 650.9 & 49 & 773.8 & 325.7 & 163.1 & 1998.0 & 51 & 2845 & 1570 & 793.8 & 8181 \\
\hline 1-OOPs/CHE & 26 & 62.1 & 13.3 & 36.1 & 90.5 & 46 & 61.8 & 21.1 & 23.6 & 99.9 & 49 & 68.1 & 15.5 & 27.9 & 95.6 & 51 & 79.9 & 11.0 & 45.2 & 97.7 \\
\hline Service coverage & 26 & 40.0 & 6.44 & 29 & 55 & 46 & 55.4 & 10.6 & 33 & 77 & 49 & 67.2 & 8.4 & 36 & 78 & 51 & 76.3 & 4.8 & 63 & 80 \\
\hline GDP per capita & 26 & 1577 & 583 & 583 & 2828 & 46 & 5191 & 2472 & 1762 & 11349 & 49 & 14436 & 5116 & 6819 & 31543 & 51 & 40678 & 20052 & 16361 & 12086 \\
\hline Gini coefficient & 25 & 41.3 & 6.64 & 32.8 & 56.2 & 44 & 38.9 & 7.2 & 25 & 57.1 & 39 & 40.0 & 10.1 & 16.6 & 63 & 38 & 32.9 & 5.3 & 25.4 & 47.7 \\
\hline Education & 26 & 9.6 & 1.85 & 5.3 & 12.6 & 46 & 11.6 & 1.9 & 6.2 & 15 & 49 & 13.7 & 1.6 & 9.2 & 17.4 & 51 & 16.2 & 2.0 & 12.7 & 23.3 \\
\hline Electricity & 26 & 31.6 & 21.3 & 7.3 & 87.21 & 46 & 76.7 & 23.4 & 22.2 & 100 & 49 & 94.3 & 12.7 & 42 & 100 & 51 & 99.9 & 0.5 & 96.8 & 100 \\
\hline Governance & 26 & -0.8 & 0.4 & -1.6 & -0.04 & 46 & -0.5 & 0.5 & -1.9 & 0.6 & 49 & -0.3 & 0.6 & -1.8 & 0.9 & 51 & 1.0 & 0.6 & -0.4 & 1.9 \\
\hline Urban population & 26 & 33.1 & 12.2 & 12.1 & 58.53 & 46 & 43.7 & 17.1 & 13.0 & 77.4 & 49 & 64.0 & 16.6 & 18.5 & 91.5 & 51 & 76.8 & 16.4 & 25 & 100 \\
\hline Log of population & 26 & 9.5 & 1.11 & 6.9 & 11.54 & 46 & 9.0 & 2.2 & 4.7 & 14.10 & 49 & 9.0 & 2.0 & 4.7 & 14.1 & 51 & 8.7 & 1.8 & 4.5 & 12.7 \\
\hline Population density & 26 & 126.7 & 134.8 & 7.3 & 471.4 & 46 & 129.8 & 187.3 & 1.9 & 1238.4 & 49 & 123.6 & 224.1 & 3.0 & 1394.7 & 51 & 354.7 & 1110.6 & 3.1 & 7806.8 \\
\hline $\begin{array}{l}\text { Health worker } \\
\text { density }\end{array}$ & 26 & 1.2 & 1.2 & 0.2 & 6.0 & 46 & 8.1 & 8.7 & 0.5 & 32.4 & 49 & 18.6 & 14.2 & 1.0 & 74.8 & 51 & 34.4 & 30.7 & 9.3 & 239.2 \\
\hline Beds & 26 & 7.1 & 4.8 & 1 & 22 & 46 & 21.3 & 18.4 & 4 & 88 & 49 & 32.3 & 21.9 & 8 & 110 & 51 & 43.4 & 24.0 & 12 & 134 \\
\hline
\end{tabular}

Notes: $S C=$ Service coverage; GGHE-D/CHE = Domestic General Government Health Expenditure as a \% of current health expenditure; CHE = current health expenditure (lagged and averaged) 


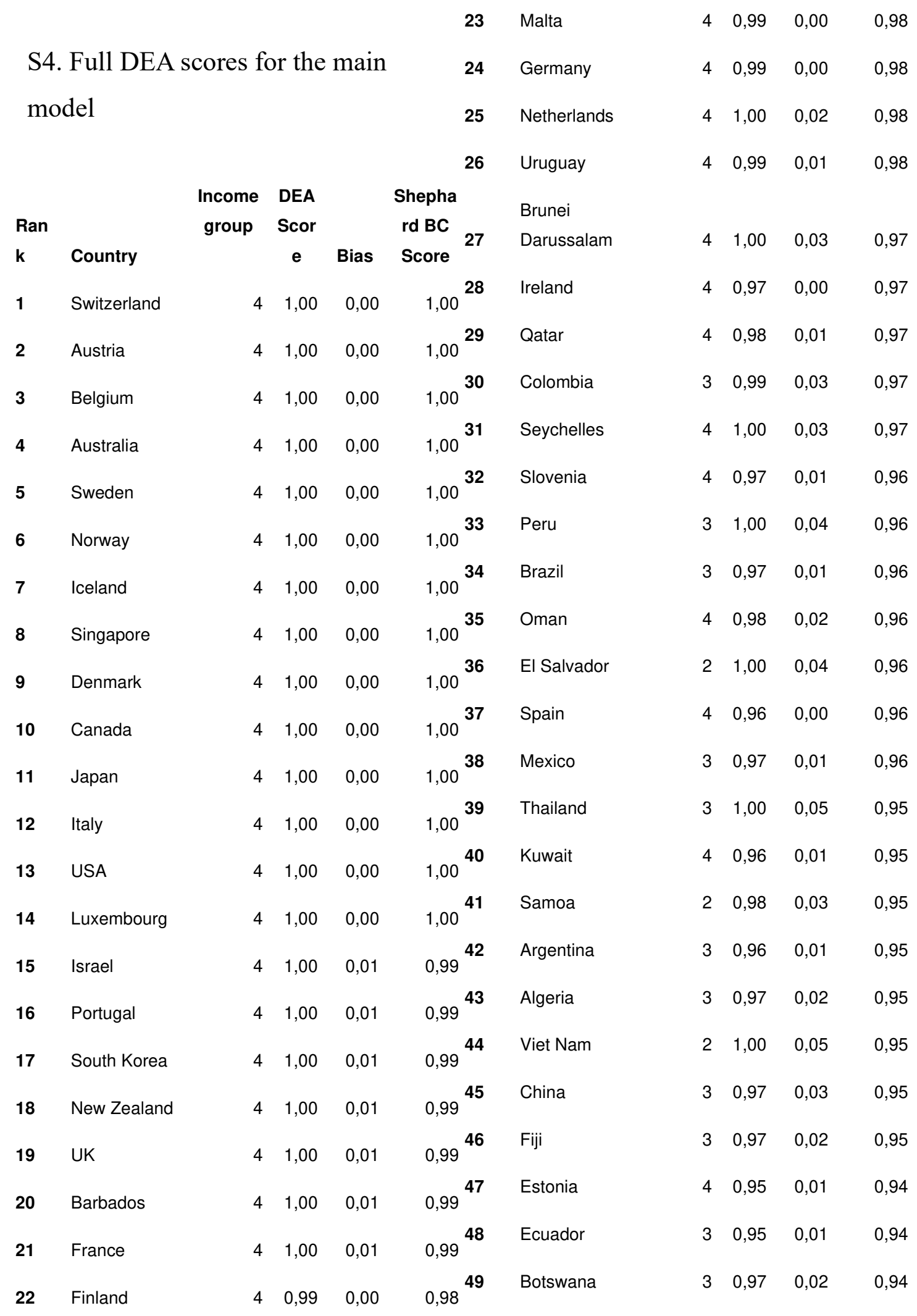




\begin{tabular}{|c|c|c|c|c|c|c|c|c|c|c|}
\hline 50 & Slovakia & 4 & 0,95 & 0,01 & 0,9475 & Kyrgyzstan & 2 & 0,95 & 0,04 & 0,90 \\
\hline & Antigua and & & & & 76 & Turkey & 3 & 0,93 & 0,03 & 0,90 \\
\hline 51 & Barbuda & 4 & 0,96 & 0,02 & ${ }^{0,94} 77$ & Jordan & 3 & 0,94 & 0,04 & 0,90 \\
\hline \multirow[t]{2}{*}{52} & Uzbekistan & 2 & 0,98 & 0,04 & 0,94 & Sao Tome & & & & \\
\hline & Dominican & & & & 78 & and Principe & 2 & 0,93 & 0,03 & 0,90 \\
\hline 53 & Republic & 3 & 0,96 & 0,02 & ${ }^{0,94} 79$ & Bahamas & 4 & 0,91 & 0,01 & 0,90 \\
\hline 54 & Costa Rica & 3 & 0,95 & 0,01 & ${ }^{0,94}$ & Eswatini & 2 & 0,92 & 0,03 & 0,90 \\
\hline 55 & South Africa & 3 & 0,96 & 0,03 & ${ }^{0,94} 81$ & Czechia & 4 & 0,91 & 0,02 & 0,89 \\
\hline 56 & $\begin{array}{l}\text { Solomon } \\
\text { Islands }\end{array}$ & 2 & 0,99 & 0,05 & $0,93^{82}$ & Kazakhstan & 3 & 0,91 & 0,01 & 0,89 \\
\hline 57 & Poland & 4 & 0,94 & 0,01 & $0,93^{83}$ & Bahrain & 4 & 0,90 & 0,01 & 0,89 \\
\hline 58 & Panama & 3 & 0,95 & 0,01 & $0,93^{84}$ & Kenya & 2 & 0,94 & 0,06 & 0,89 \\
\hline 59 & Tajikistan & 2 & 1,00 & 0,07 & $0,93^{85}$ & Saudi Arabia & 4 & 0,90 & 0,01 & 0,89 \\
\hline \multirow[t]{2}{*}{60} & Micronesia & 2 & 0,96 & 0,03 & $0,93^{86}$ & Malaysia & 3 & 0,89 & 0,01 & 0,88 \\
\hline & Trinidad and & & & & 87 & Egypt & 2 & 0,90 & 0,02 & 0,88 \\
\hline 61 & Tobago & 4 & 0,94 & 0,01 & 0,9388 & Timor-Leste & 2 & 0,94 & 0,06 & 0,88 \\
\hline 62 & Kiribati & 2 & 1,00 & 0,07 & 0,93 & North & & & & \\
\hline 63 & Belarus & 3 & 0,94 & 0,01 & $0,93^{89}$ & Macedonia & 3 & 0,89 & 0,02 & 0,87 \\
\hline 64 & Tonga & 2 & 0,96 & 0,04 & $0,92^{90}$ & Bhutan & 2 & 0,90 & 0,03 & 0,87 \\
\hline 65 & Venezuela & 3 & 0,95 & 0,02 & $0,92^{91}$ & Vanuatu & 2 & 1,00 & 0,13 & 0,87 \\
\hline 66 & Namibia & 3 & 0,95 & 0,02 & $0,92^{92}$ & Chile & 4 & 0,88 & 0,01 & 0,87 \\
\hline 67 & Suriname & 3 & 0,94 & 0,02 & $0,92^{93}$ & Hungary & 4 & 0,88 & 0,01 & 0,87 \\
\hline 68 & Romania & 3 & 0,93 & 0,02 & $0,91^{94}$ & Greece & 4 & 0,87 & 0,01 & 0,87 \\
\hline 69 & Cabo Verde & 2 & 0,94 & 0,02 & $0,91^{95}$ & Paraguay & 3 & 0,88 & 0,02 & 0,87 \\
\hline 70 & Nicaragua & 2 & 0,94 & 0,03 & $0,91^{96}$ & Saint Lucia & 3 & 0,88 & 0,02 & 0,86 \\
\hline 71 & Croatia & 4 & 0,93 & 0,02 & $0,91^{97}$ & Malawi & 1 & 0,94 & 0,08 & 0,86 \\
\hline 72 & Cyprus & 4 & 0,91 & 0,01 & $0,91^{98}$ & Lebanon & 3 & 0,86 & 0,01 & 0,85 \\
\hline 73 & Guyana & 3 & 0,94 & 0,04 & $0,90^{99}$ & Morocco & 2 & 0,87 & 0,03 & 0,84 \\
\hline \multirow[t]{2}{*}{74} & Grenada & 3 & 0,92 & 0,02 & $0,90^{100}$ & Armenia & 2 & 0,85 & 0,01 & 0,84 \\
\hline & & & & & 101 & UAE & 4 & 0,85 & 0,01 & 0,84 \\
\hline
\end{tabular}


St Vincent

and the

102 Grenadines

103 Zimbabwe

104 Bolivia

105 Zambia

106 Turkmenistan

107 Honduras

108 Lithuania

109 Rwanda

110 Georgia

111 Moldova

112 Lesotho

113 Belize

114 Myanmar

115 Sri Lanka

116 Burundi

117 Maldives

118 Iran

119 Iraq

120 Serbia

121 Mongolia

122 Ukraine

123 Tunisia

124 Bangladesh

125 Jamaica

126 Mauritius

127 Azerbaijan

128

Bulgaria
$3 \quad 0,86 \quad 0,02$

$1 \quad 0,88 \quad 0,04$

$2 \quad 0,87 \quad 0,03$

$20,88 \quad 0,05$

$3 \quad 0,85 \quad 0,02$

$2 \quad 0,87 \quad 0,04$

$4 \quad 0,84 \quad 0,01$

$1 \quad 0,89 \quad 0,06$

$3 \quad 0,85 \quad 0,01$

$2 \quad 0,86 \quad 0,03$

$2 \quad 0,86 \quad 0,03$

$\begin{array}{lll}3 & 0,86 & 0,03\end{array}$

$2 \quad 0,87 \quad 0,04$

$2 \quad 0,86 \quad 0,03$

$1 \quad 0,97 \quad 0,14$

$3 \quad 0,84 \quad 0,02$

$3 \quad 0,82 \quad 0,01$

$\begin{array}{lll}3 & 0,84 & 0,03\end{array}$

$3 \quad 0,82 \quad 0,01$

$2 \quad 0,84 \quad 0,03$

$2 \quad 0,84 \quad 0,03$

$2 \quad 0,83 \quad 0,02$

$2 \quad 0,88 \quad 0,07$

$3 \quad 0,83 \quad 0,03$

$3 \quad 0,81 \quad 0,01$

$3 \quad 0,81 \quad 0,01$

$3 \quad 0,81 \quad 0,01$
129 Libya

0,84 130 Gabon

$0,84^{131}$ Latvia

$0,84^{132}$ Congo

$0,84^{133}$ Russia

0,84134 Mozambique

0,84

Equatorial

0,83

136 Cambodia

0,83

137 India

0,83

138 Gambia

0,83

0,83

140 Philippines

0,83

141 Comoros

0,83

0,83 142 Herzegovina

0,82 143 Haiti

0,82

Laos

144 Republic

0,81145 Guatemala

$0,81^{146}$ Angola

$0,81^{147}$ Ghana

0,81 148 Ethiopia

$0,81^{149}$ Tanzania

0,81150 Benin

$0,81^{151 \quad \text { Togo }}$

$0,80^{152 \text { Nepal }}$

0,80

153 Uganda

$0,80^{154}$ Senegal $\begin{array}{llll}3 & 0,84 & 0,04 & 0,80\end{array}$

$\begin{array}{llll}3 & 0,82 & 0,02 & 0,80\end{array}$

$\begin{array}{llll}4 & 0,81 & 0,01 & 0,80\end{array}$

$2 \quad 0,84 \quad 0,04 \quad 0,79$

$\begin{array}{llll}3 & 0,80 & 0,01 & 0,79\end{array}$

$1 \quad 1,00 \quad 0,21 \quad 0,79$

$\begin{array}{llll}3 & 0,81 & 0,02 & 0,79\end{array}$

$2 \quad 0,83 \quad 0,05 \quad 0,78$

$2 \begin{array}{llll}2 & 0,83 & 0,05 & 0,78\end{array}$

$\begin{array}{llll}1 & 0,87 & 0,09 & 0,78\end{array}$

$\begin{array}{llll}3 & 0,79 & 0,02 & 0,78\end{array}$

$2 \quad 0,80 \quad 0,04 \quad 0,76$

$1 \quad 0,82 \quad 0,06 \quad 0,76$

$\begin{array}{llll}3 & 0,77 & 0,02 & 0,75\end{array}$

$\begin{array}{llll}1 & 0,82 & 0,07 & 0,75\end{array}$

$2 \quad 0,79 \quad 0,04 \quad 0,74$

$2 \quad 0,76 \quad 0,02 \quad 0,74$

$\begin{array}{llll}3 & 0,77 & 0,04 & 0,73\end{array}$

$2 \quad 0,77 \quad 0,04 \quad 0,73$

$1 \quad 0,85 \quad 0,12 \quad 0,73$

$10,82 \quad 0,09 \quad 0,73$

$1 \quad 0,80 \quad 0,08 \quad 0,72$

$\begin{array}{llll}1 & 0,78 & 0,06 & 0,72\end{array}$

$1 \quad 0,76 \quad 0,05 \quad 0,71$

$\begin{array}{llll}1 & 0,75 & 0,05 & 0,69\end{array}$

$1 \quad 0,76 \quad 0,07 \quad 0,69$ 


\begin{tabular}{|c|c|c|c|c|c|}
\hline 155 & Indonesia & 2 & 0,70 & 0,02 & 0,68 \\
\hline 156 & Cameroon & 2 & 0,71 & 0,04 & 0,67 \\
\hline 157 & Cote d'Ivoire & 2 & 0,70 & 0,03 & 0,66 \\
\hline \multirow[t]{2}{*}{158} & Liberia & 1 & 0,71 & 0,06 & 0,66 \\
\hline & Guinea- & & & & \\
\hline 159 & Bissau & 1 & 0,71 & 0,06 & 0,65 \\
\hline 160 & Burkina Faso & 1 & 0,73 & 0,07 & 0,65 \\
\hline 161 & Guinea & 1 & 0,78 & 0,13 & 0,65 \\
\hline 162 & DRC & 1 & 1,00 & 0,36 & 0,64 \\
\hline 163 & Pakistan & 2 & 0,68 & 0,04 & 0,63 \\
\hline 164 & Niger & 1 & 0,74 & 0,13 & 0,62 \\
\hline 165 & Yemen & 2 & 0,65 & 0,04 & 0,61 \\
\hline 166 & Sudan & 2 & 0,62 & 0,03 & 0,59 \\
\hline 167 & Chad & 1 & 0,65 & 0,07 & 0,58 \\
\hline \multirow[t]{3}{*}{168} & Mauritania & 2 & 0,59 & 0,04 & 0,55 \\
\hline & Central & & & & \\
\hline & African & & & & \\
\hline 169 & Republic & 1 & 1,00 & 0,48 & 0,52 \\
\hline 170 & Afghanistan & 1 & 0,54 & 0,03 & 0,51 \\
\hline 171 & Sierra Leone & 1 & 0,54 & 0,03 & 0,51 \\
\hline 172 & Mali & 1 & 0,56 & 0,06 & 0,50 \\
\hline
\end{tabular}

Notes: DRC = Democratic Republic of the Congo, UK = United Kingdom, USA = United States of America, $\mathrm{UAE}=$ United Arab Emirates 


\section{S5. Sensitivity Analysis Results}

To assess the robustness of the findings, given that DEA can produce sensitive results, an indepth sensitivity analysis was performed. The following adjustments were made to determine the robustness of results:

1) The financial protection proxy, 1-OOPs/CHE, is substituted with GGHE-D/CHE, which is a similar and alternative proxy for financial protection;

2) 3 year lags for CHE were used in place of the 5 year lagged average to test the sensitivity of the time lag;

3) Outlying countries were removed one at a time, since deterministic models like DEA do not allow for random noise and are particularly sensitive to outliers

4) Conduct Tobit regression as second stage in place of Simar-Wilson.

1) Changing the CHE year

A 3-year average variable lagged by 5 years was applied in the main model to reflect the fact that changes in health expenditure are not reflected immediately in the outcomes. To test the robustness of the CHE variable, the main model was run with 5-year and 3-year lags from a single year. Small changes are made to the efficient set, but largely the results remain the same. No changes to the bias-corrected scores of $>1 \%$ are observed. In the 3-year lag (CHE from 2012), Fiji and Madagascar are efficient in the DEA analysis prior to bias-correction and in the 5-year lag, Barbados becomes efficient. However, overall the model is robust to the choice of CHE variable.

2) Removal of outlier and efficient DMUs

Because DEA compares countries to their peers, the choice of peers made available can influence the results, particularly in the case of outliers who perform uniquely well. Therefore, to test whether any countries could be biasing the results, the Simar-Wilson regression and DEA was run individually excluding one country at a time. Countries to exclude were identified in three ways. Firstly, scatter plots and visual analysis identified nine potential outliers. Secondly, the five most extreme cases for the three input/output variables were identified using Nick Cox's extremes command on STATA. Finally, all countries with original DEA scores equal to one (fully efficient prior to bias-adjustment) were removed. Since many overlapped, this left a final set of 46 countries. 
What happened to the bias-corrected efficiency scores?

Most countries have negligible changes $(<5 \%)$ in the bias-corrected scores when removing others from the analysis. Notable exceptions are Niger, Gambia, CAR and Mali whose scores decrease by $10 \%$ when Vanuatu and Mozambique are removed, and DRC whose score increases by $10 \%$ when New Zealand is removed.

What happened to the double bootstrap regression results (determinants of efficiency)?

For all countries, the significant determinants of UHC provision efficiency remained the same when removing outliers - income, education and governance are significant.

3) Change in financial protection proxy to GGHE-D/CHE

Another measure of financial protection could be domestic general government expenditure as a proportion of current health expenditure. GGHE-D should be similar to 1-OOPs as it is the proportion of expenditure not attributed to OOP. The financial protection proxy indicator is therefore replaced by GGHE-D/CHE and the model is re-run. The results showed the exact same set in the high income group and some slight changes to the efficient sets of the other income groups, particularly the low income one. In this permutation, electricity access becomes a significant determinant of UHC efficiency and income is not significant at the $10 \%$ level.

\section{Summary of 46 Sensitivity Analysis Graphs}

There are only three cases in 46 models for 172 countries that have an average variation of more than $5 \%$ in the bias-corrected efficiency score. There are few examples where the removal of one outlier results in an up to $18 \%$ change. The largest variation is seen in the low income group. The main model is largely robust to removing outlier/efficient countries, changing the input to GGHE-D from 1-OOPs/CHE and changing the lag in CHE. 


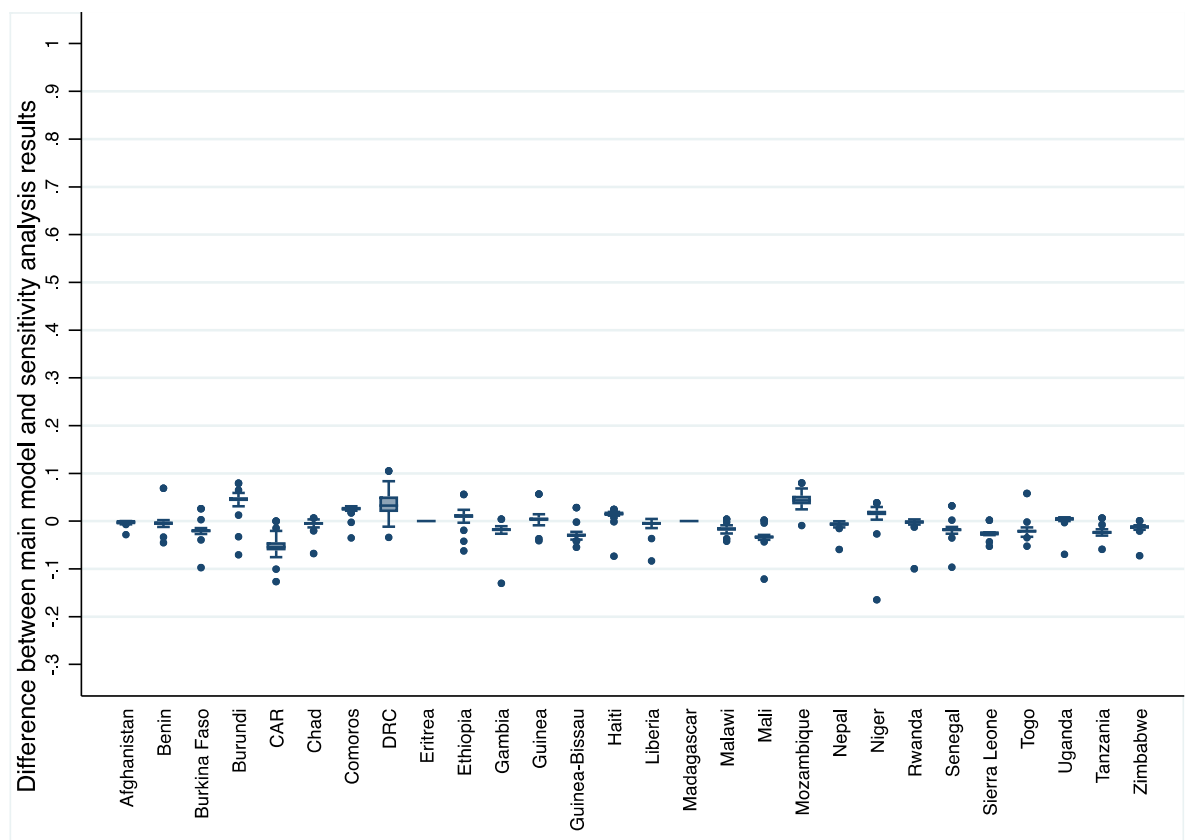

Figure 2: Summary of sensitivity analysis for low income countries

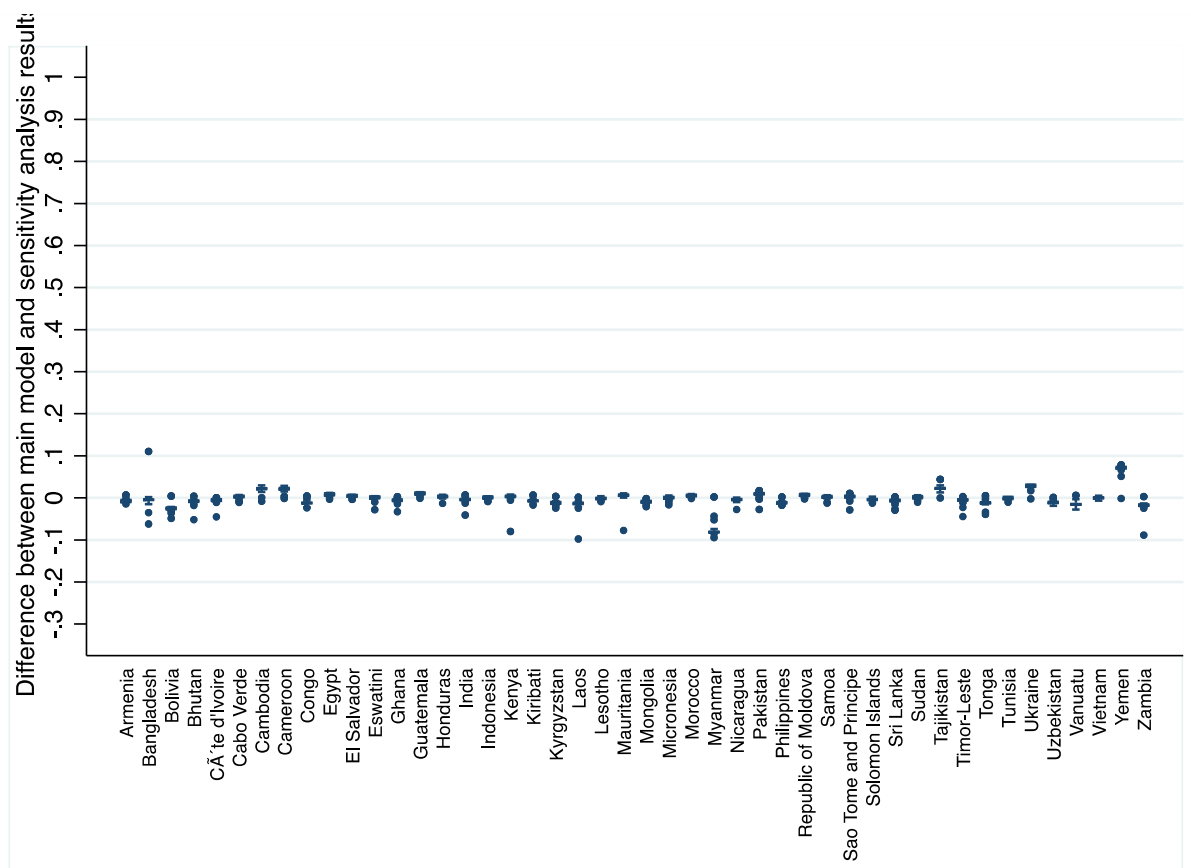

Figure 3: Summary of sensitivity analysis for lower-middle income countries 


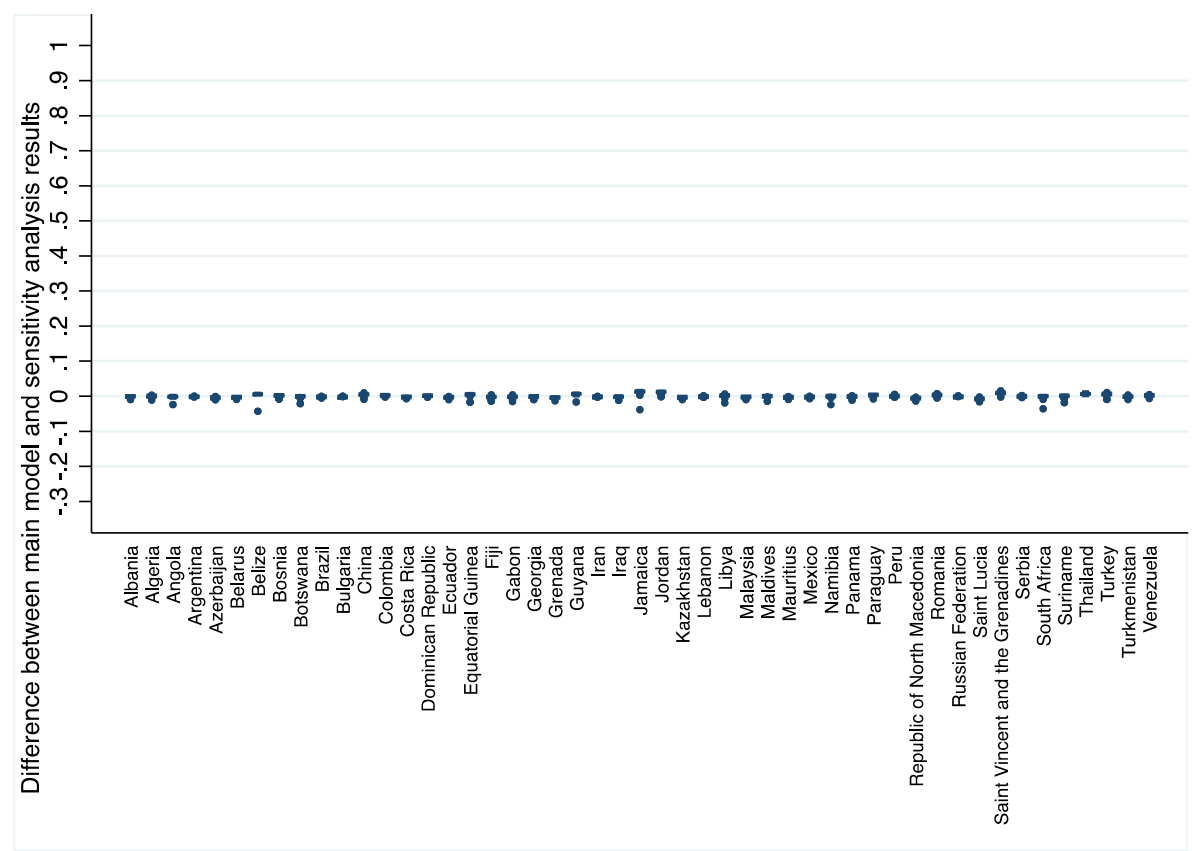

Figure 4: Summary of sensitivity analysis for upper-middle income countries

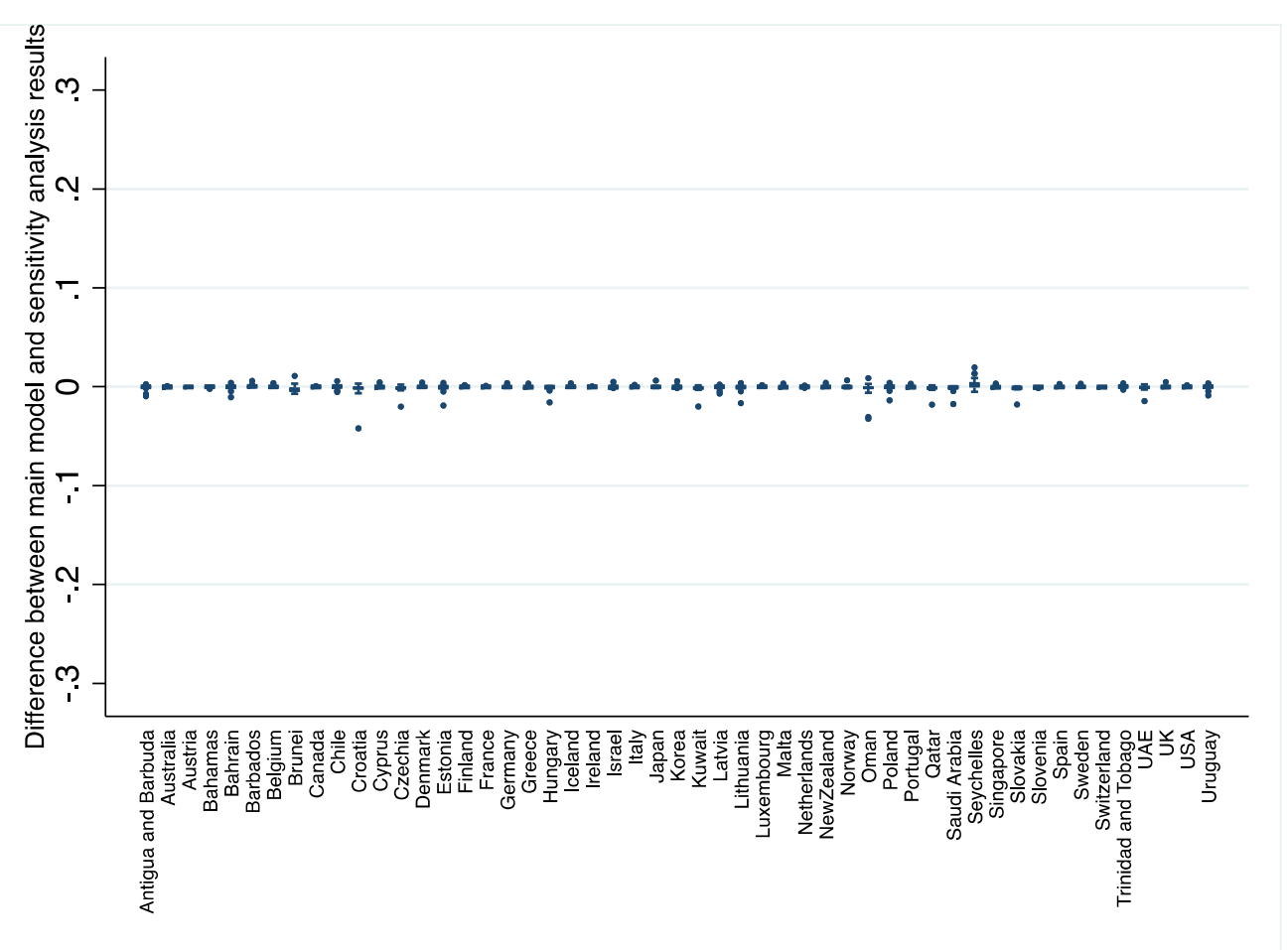

Figure 5: Summary of sensitivity analysis for high income countries 
4) Tobit Regression in second-stage

Results using a Tobit regression instead of Simar-Wilson

\begin{tabular}{|c|c|c|c|c|}
\hline \multirow{2}{*}{ Variable } & \multirow{2}{*}{ Coefficient $(\beta)$} & \multirow{2}{*}{$\begin{array}{l}\text { Standard Error } \\
\qquad(\sigma)\end{array}$} & \multicolumn{2}{|c|}{ 95\% Confidence Interval } \\
\hline & & & Lower Bound & Upper Bound \\
\hline GDP & $4.59 \times 10^{-7}$ & $4.40 \times 10^{-7}$ & $-4.09 \times 10^{-7}$ & $1.33 \times 10^{-6}$ \\
\hline EDUCATION & $0.0144225 * * *$ & 0.0040104 & 0.0065034 & 0.0223416 \\
\hline ELECTRICITY & $0.0010888 * * *$ & 0.0002952 & 0.000506 & 0.0016717 \\
\hline LOGPOP & -0.0051103 & 0.0031084 & -0.0112482 & 0.0010276 \\
\hline POPDENSITY & $1.35 \times 10^{-6}$ & $9.24 \times 10^{-6}$ & -0.0000169 & 0.0000196 \\
\hline URBANPOP & -0.0000762 & 0.0003775 & -0.0008216 & 0.0006692 \\
\hline GOVERNANCE & $0.0275269^{*}$ & 0.0113006 & 0.0052124 & 0.0498414 \\
\hline HEALTHWORKER & 0.0000572 & 0.0003135 & -0.0005619 & 0.0006763 \\
\hline BEDS & 0.0000859 & 0.0002909 & -0.0004884 & 0.0006603 \\
\hline Constant & $0.6132538 * * *$ & 0.046964 & 0.5205175 & 0.7059901 \\
\hline
\end{tabular}

